International Journal of Trend in Scientific Research and Development (IJTSRD)

Volume: 3 | Issue: 3 | Mar-Apr 2019 Available Online: www.ijtsrd.com e-ISSN: 2456 - 6470

\title{
Design and Fabrication of Thermo Electric Refrigerator
}

\author{
Dr. S. Sreenatha Reddy1, G. Naveen Kumar'2, K. Sridhar², M. Sai Siri² \\ 1Principal, ${ }^{2}$ Student \\ 1,2Department of Mechanical Engineering, Guru Nanak Institute of Technology, Hyderabad, India
}

\begin{abstract}
How to cite this paper: Dr. S. Sreenatha Reddy | G. Naveen Kumar | K. Sridhar | M. Sai Siri "Design and Fabrication of Thermo Electric Refrigerator" Published in International Journal of Trend in Scientific Research and Development (ijtsrd), ISSN: 24566470, Volume-3 | Issue-3, April 2019, pp.1299-1304, URL: https://www.ijtsrd.c om/papers/ijtsrd23 356.pdf

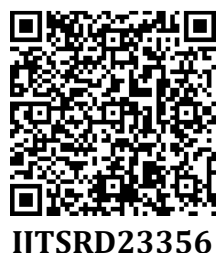

Copyright (C) 2019 by author(s) and International Journal of Trend in Scientific Research and Development Journal. This is an Open Access article distributed under the terms of the Creative Commons

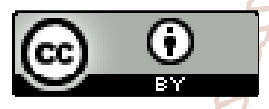
Attribution License (CC BY 4.0) (http://creativecommons.org/licenses/ by/4.0)

\section{INTRODUCTION}

There are several methods which can be employed to facilitate the transfer of heat from the surface of the thermoelectric to the surrounding. Electrons can travel freely in the copper conductors but not so freely in the semiconductor. As the electrons leave the copper and enter the hot side of the p-type, they must fill a "hole" in order to move through the p-type. When the electrons fill a hole, they drop down to a lower energy level and release heat in the process. Then as the electrons move from the p-type into the copper conductor on the cold side, the electrons are bumped back to a higher energy level and absorb heat in the process the electrons move freely through the copper until they reach the cold side of the n-type semiconductor. When the electrons move into the n-type, they must bump up an energy level in order to move through the semiconductor. Heat is absorbed when this occurs. Finally, when the electrons leave the hot-side of the n-type, they can move freely in the copper. They drop down to a lower energy level and release heat in the process. To increase heat transport, several $\mathrm{p}$ type or $\mathrm{n}$ type thermoelectric (TE) components can be hooked up in parallel. The TE components can be put in series but the heat transport abilities are diminished because the interconnecting's between the semiconductors creates thermal shorting. The most efficient configuration is where a $\mathrm{p}$ and $\mathrm{n}$ TE component is put electrically in series but thermally in parallel. The device to the right is called a couple.
ABSTRACT

In the recent years, we have many problems such as energy crises and clean and environment friendly system. The main advantage of the two electrically dissimilar materials heat is absorbed or liberated at the junction. germanium and its alloys. The main objective is to design and fabrication of

KEYWORDS: Thermo electric module, Peltier effect 
Manoj and Walke conducted an experimental study of thermoelectric air cooling for cars. They are trying to overcome these demerits by replacing the existing HVAC system with newly emerging thermoelectric couple or cooler which works on Peltier and seebeck effect [2].

Yadav and Mehta presented combined experimental and theoretical study of thermoelectric materials and application. The present study develops an optimization design method for thermoelectric refrigerator. This device is fabricated by combining the standard n-channel and pchannel solid-state thermoelectric cooler with a two-element device inserted into each of the two channels to eliminate the solid-state thermal conductivity [3].

Maneewan conducted an experimental investigation of thermal comfort study of compact thermoelectric air conditioner. In this paper analyse the cooling performance of compact thermoelectric air-conditioner. TEC1-12708 type thermoelectric modules used for heating and cooling application [4].

Huang. B conducted an experimental study of design method of thermoelectric cooler. They are fabricated the thermoelectric cooler and analyse various considerations. The system simulation shows that there exists a cheapest heat sink for the design of a thermoelectric cooler. It is also shown that the system simulation coincides with experimental data of a thermoelectric cooler [5].

\section{MATERIAL AND METHODOLOGY}

Materials used in our work include Peltier module, aluminium foil, heat sink, cooling fan, plywood and temperature sensor.

\section{Peltier Module}

In this thermal energy could be absorbed at one junction and discharged at the other junction when an electric current flowed within the closed circuit. The most commonly used Peltier modules in the all applications are TEC1-12706, TEC1-12704, TEC1-12708. The Peltier unit in this fridge is TEC1-12706. This work on 12V DC and takes maximum current of 6 amps at full load. The power rating of this unit is 92 watts.

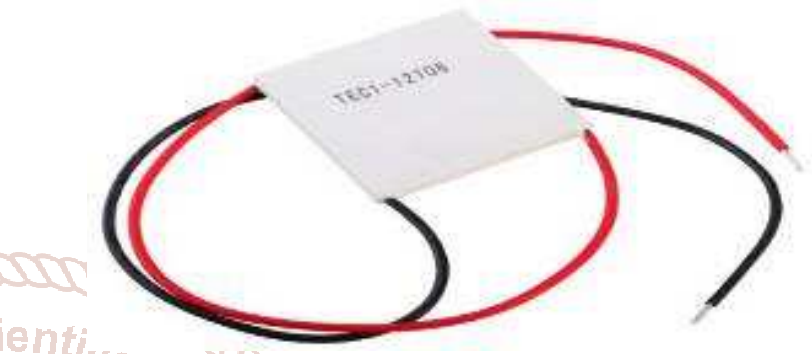

Fig 2: Peltier module

Specifications of Peltier module TEC1-12706

\begin{tabular}{|l|l|l|l|}
\hline $\mathrm{T}_{\mathrm{h}}\left({ }^{\mathrm{o}} \mathrm{C}\right)$ & 27 & 50 & Hot side temperature at environment: dry air, $\mathrm{N}_{2}$ \\
\hline $\mathrm{DT}_{\max }\left({ }^{\mathrm{o}} \mathrm{C}\right)$ & 70 & 79 Inte & $\begin{array}{l}\text { Temperature Difference between cold and hot side of the } \\
\text { module when cooling capacity is zero at cold side }\end{array}$ \\
\hline $\mathrm{U}_{\max }$ (Voltage) & 16.0 & 17.2 & Voltage applied to the module at $\mathrm{DT}_{\max }$ \\
\hline $\mathrm{I}_{\max }$ (amps) & 6.1 & 6.1 & DC current through the modules at $\mathrm{DT}_{\max }$ \\
\hline $\mathrm{Q}_{\mathrm{Cmax}}$ (Watts) & 61.4 & 66.7 & Cooling capacity at cold side of the module under $\mathrm{DT}=0 \stackrel{\circ}{\circ}$ \\
\hline AC resistance(ohms) & $1.8 \sim 2.2$ & $2.0 \sim 2.4$ & The module resistance is tested under AC \\
\hline
\end{tabular}

\section{Cooling Fan}

The fans used in this fridge works on $12 \mathrm{~V}$ DC and draws 0.18 amps. The power consumption of each fan is 2.16 watts.

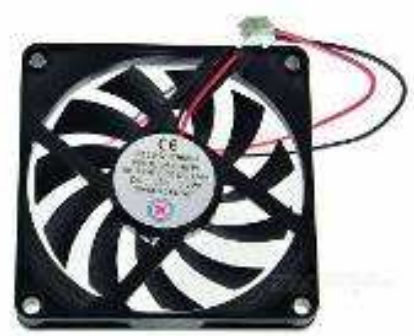

Fig 3: Cooling fan

\section{Heat Sink}

Heat sink is a passive heat exchanger that transfers the heat generated by an electronic or a mechanical device to a fluid medium, often air or a liquid coolant, where it is dissipated away from the device, thereby allowing regulation of the device's temperature at optimal levels.

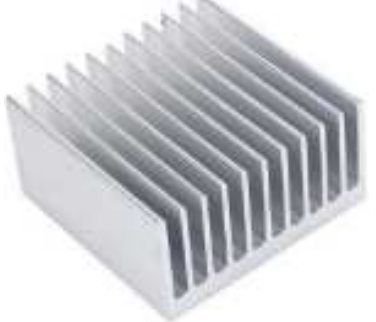

Fig 4: Heat sink

\section{Aluminium foil}

Aluminium foil is widely used for radiation shield (barrier and reflectivity), heat exchangers (heat conduction) and cable liners (barrier and electrical conductivity). Aluminium foil's heat conductive qualities make it a common accessory in hookah smoking: a sheet of perforated aluminium foil is frequently placed between the coal and the tobacco, allowing the tobacco to be heated without coming into direct contact with the burning coal.

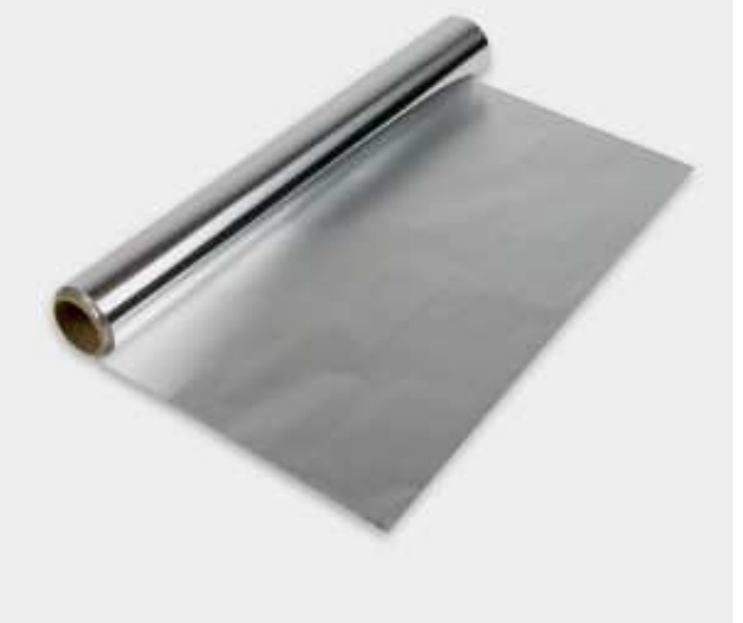

Fig 5: Aluminium foil 


\section{Plywood}

Plywood is a material manufactured from thin layers of wood veneer that are glued together with adjacent layers having their wood grain rotated up to 90 degrees to one another.

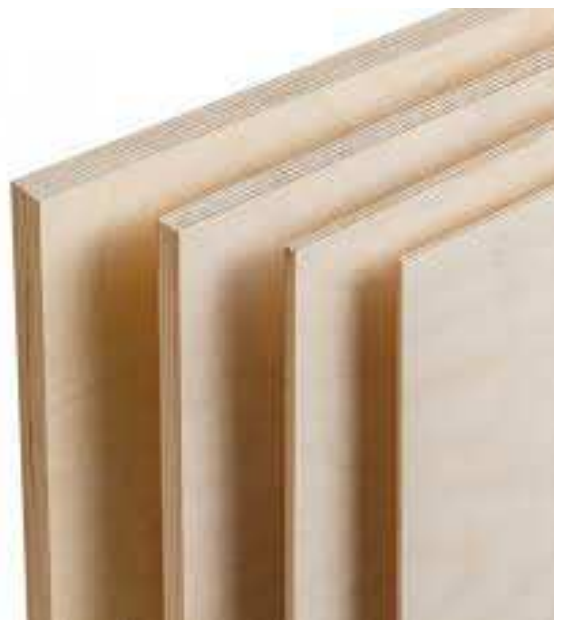

Fig 6: Plywood

\section{Temperature sensor}

The temperature sensor is a device which is used to sense the temperature of the refrigeration box and give us the accurate data about the rate of cooling of the box. It is an important device which is gives us the information about the cooling rate of the box and it also helps us to calculate the efficiency of the device i.e. thermoelectric refrigerator.

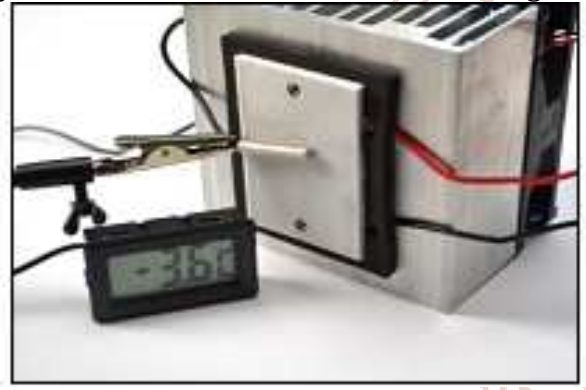

Fig 7: Temperature sensor

Designing of Refrigerator Body by SOLID WORKS 2016 Starting of SOLID WORKS 2016 is with a new name which will be displayed on the screen.

To start a new file in the part design workbench, choose file from the menu bar. The new dialog box is displayed. After accomplishment all the necessary cuttings and modifications of the refrigerator body, the ultimate model looks as shown in figure.

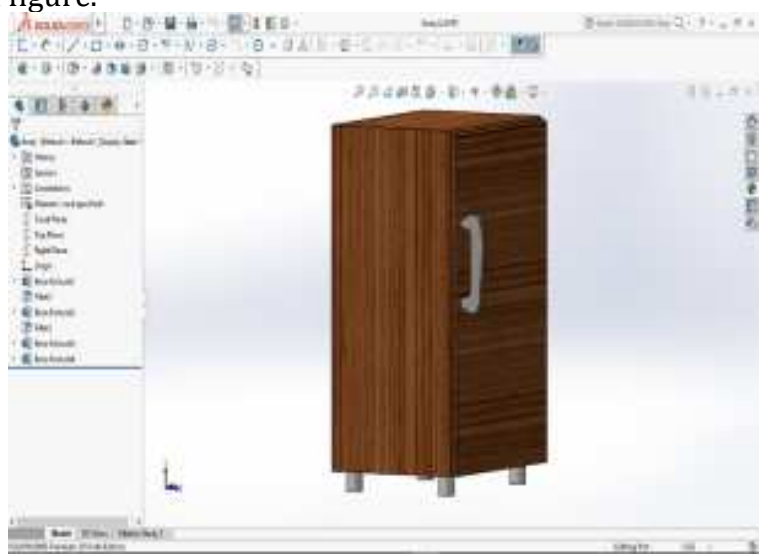

Fig 8: Refrigerator body

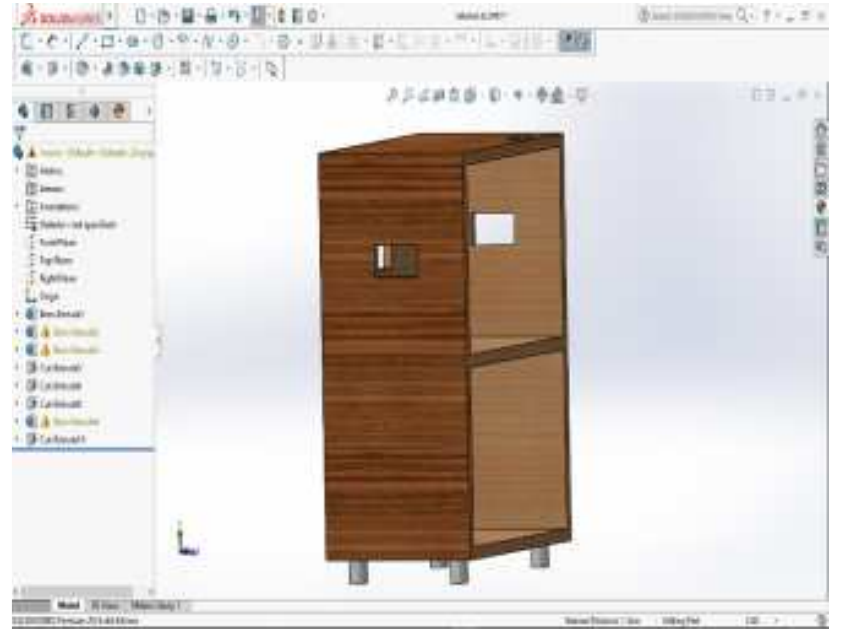

Fig 9: Refrigerator body interior

\section{FABRICATION}

In this section we will discuss about the various design procedures that we have followed in the fabrication of the thermoelectric refrigerator.

\section{Step 1: Making of refrigerator box}

The first step is to make the refrigeration box. Firstly, we have taken the thermacol box for the purpose of refrigeration. After that the insulation is done on the both sides. On the outer side the insulation is done with the wooden ply of thickness $5 \mathrm{~mm}$ and on the inner side the insulation is done with the aluminium sheet of thickness $1 \mathrm{~mm}$. The insulation is done to ensure that the box will remain cool properly and there is no loss of heat to the surroundings.

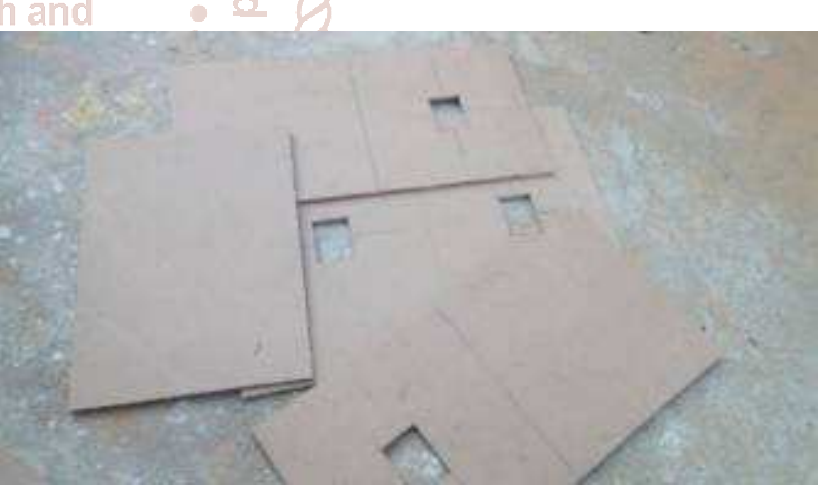

Fig 10: Plywood pieces before fabrication

\section{Step 2: Cutting process}

After the box has been made the back side of the box is cut in the proper dimensions to fit the fin-fan assembly in it.

\section{Step 3: Drilling}

Drilling is done on both the fins i.e. hot and cold side fins. The drilling is done to hold the both fins together tightly. The drilling is done by holding the both fins in a clamp tightly and after that the drilling is done on the drilling machine very precisely. 


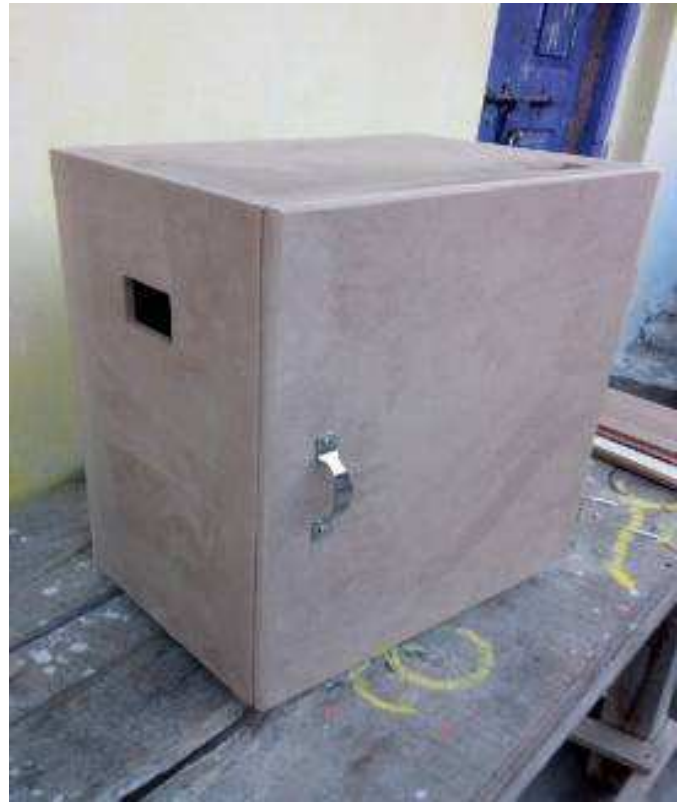

Fig 11: Refrigerator body after fabrication

\section{Step 4: Mounting of thermoelectric module}

Mounting of module must be done with utter most care. The surface of the fin, to be attached to the Peltier Module is wiped free off dirt and grease using alcohol or similar and thin film of thermally conductive silicon grease on the suitable surfaces. The thermoelectric module is then attached to the fin with the help of glue

\section{Step 5: Tightening of screws}

After the thermoelectric module is sandwiched between the fins both fins are tightened together with the help of screws in the holes which are drilled previously. The screws are tightened precisely, and the excess part of the screw is cut.

\section{Step 6: Mounting of fin fan assembly}

After the fins are tightened together the fans are attached to them and the whole assembly is mounted on the back side of the refrigeration box. The assembly is mounted in such a way that the cold side fin is inside the box and hot side fin is outside the box. The Peltier module is between the both fins.

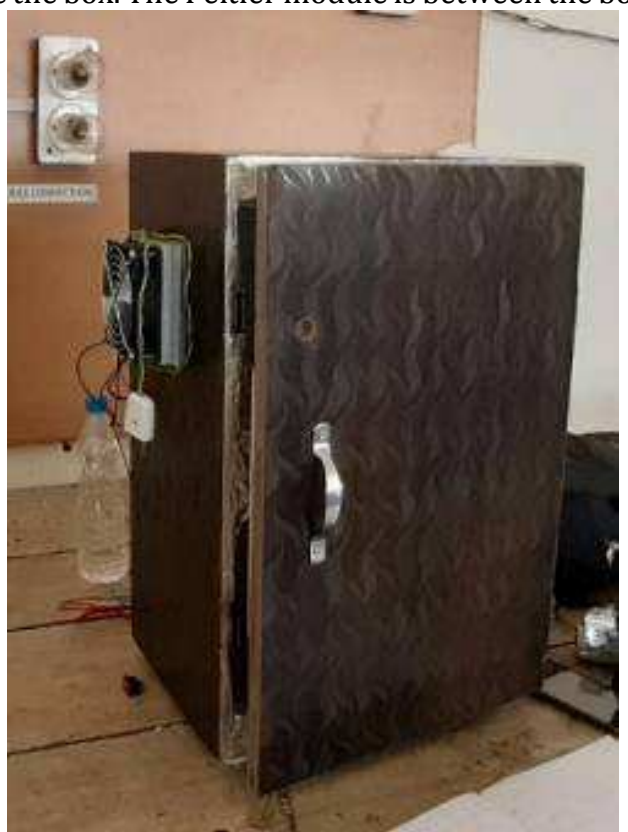

Fig 12: Refrigerator body after fabrication with Peltier modules

\section{Step 7: Selection of power supply}

Now the circuit controller is mounted on the backside of box. The circuit controller is used as a power supply source. Both the fans and the Peltier module are attached to the circuit controller with the help of wires. The black wire is positive and red is negative. Here we have used the $12 \mathrm{~V}$ dc power supply.

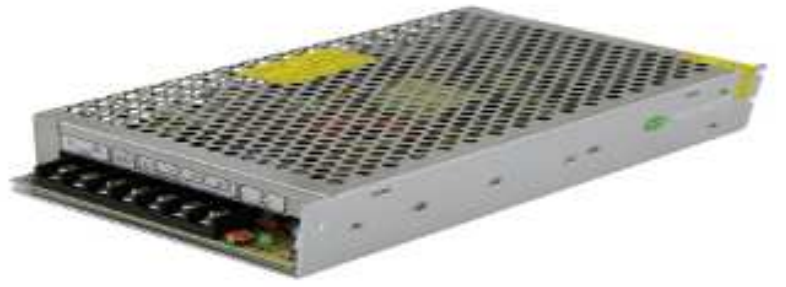

Fig 13: Power supply

\section{WORKING \\ Circuit Diagram}

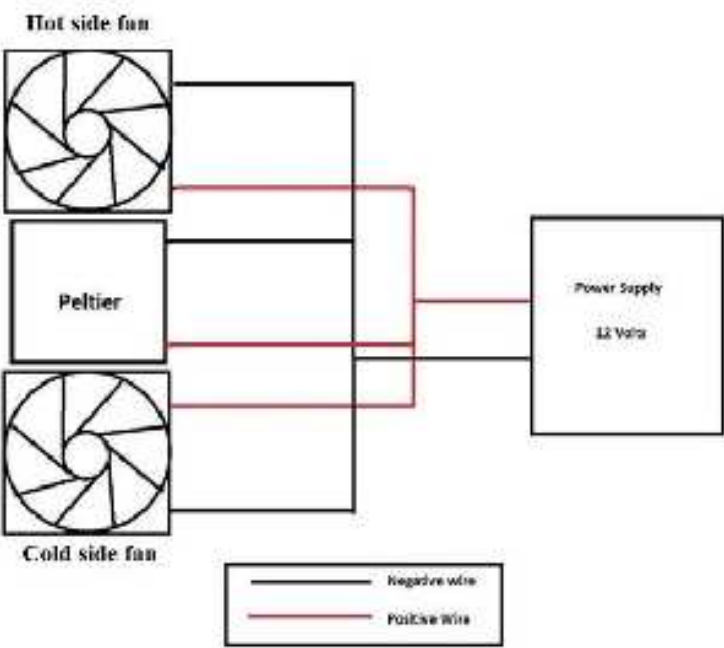

Fig 14: Circuit Diagram

In circuit diagram we can see that the Peltier is placed between the hot side fan and the cold side fan. Both the Peltier device and the fans are connected to the $12 \mathrm{~V}$ power supply. Here the power supply is direct current (D.C.) because the Peltier device is a semiconductor device. The red wire is positive, and the black is negative. As the Peltier gets the power supply its one end gets hot and the other gets cold which is the basis of the working of our thermoelectric refrigerator. working the refrigerator is provided with a power supply of 12 volts and 10 amps DC current.

\section{Working of TER}

1. To start the refrigerator, the switch on the fridge is turned ON.

2. When the switch is turned on the Peltier devices and fan start functioning.

3. Cold sides of the four Peltier devices transfers the chilling effect to the evaporator.

4. Hot side of the Peltier are exposed to the atmosphere so that a fan will takes out the heat from hot side at faster rate.

5. The Peltier thermo electric device will be arranged in a box with proper insulation system and heat sink so that efficient cooling takes place at all the time.

6. To turn off the refrigerator, switch can be turned OFF. 


\section{RESULTS AND DISCUSSION}

COP of TEM (Thermo electric module)

Heat Absorption $\left(\mathrm{Q}_{\mathrm{c}}\right)=\alpha \mathrm{IT}_{\mathrm{C}}-0.5 \mathrm{I}^{2} \mathrm{R}-\mathrm{K}_{\mathrm{t}}\left(\mathrm{T}_{\mathrm{h}}-\mathrm{T}_{\mathrm{C}}\right)$

Heat Rejection $\left(\mathrm{Q}_{\mathrm{h}}\right)=\alpha \mathrm{IT}_{\mathrm{h}}+0.5 \mathrm{I}^{2} \mathrm{R}-\mathrm{K}_{\mathrm{t}}\left(\mathrm{T}_{\mathrm{h}}-\mathrm{T}_{\mathrm{C}}\right)$

Where $\alpha=$ Seeback Coefficient in $\mathrm{VK}^{-1}$

$\mathrm{I}=$ Current in amps

$\mathrm{R}=$ electrical resistance of the TEM in $\Omega$

$\mathrm{K}_{\mathrm{t}}=$ thermal conductivity of TEM in $\mathrm{Wm}^{-1} \mathrm{~K}^{-1}$

$\mathrm{T}_{\mathrm{c}}=$ Cold side temperature in $\mathrm{K}^{-1}$

$\mathrm{T}_{\mathrm{h}}=$ Hot side temperature in $\mathrm{K}^{-1}$

Coefficient of performance $(\mathrm{COP})=\mathrm{Q}_{\mathrm{c}} / \mathrm{Q}_{\mathrm{h}}-\mathrm{Q}_{\mathrm{c}}$

$\alpha=53 \mathrm{VK}^{-1} \mathrm{I}=10 \mathrm{~A} \mathrm{R}=2.1 \Omega$

$\mathrm{K}_{\mathrm{t}}=0.025 \mathrm{Wm}^{-1} \mathrm{~K}^{-1}$

$\mathrm{T}_{\mathrm{c}}=10^{\circ} \mathrm{C}=283^{\circ} \mathrm{K}$

$\mathrm{T}_{\mathrm{h}}=53^{\circ} \mathrm{C}=326^{\circ} \mathrm{K}$

Heat Absorption $\left(Q_{c}\right)=53 * 10 * 283-0.5(10)^{2} * 2.1-$ 0.025(326-283)

$$
\begin{aligned}
& =149883.9 \text { Joules } \\
& =150 \mathrm{KJ}
\end{aligned}
$$

For 4 Peltier modules $\mathrm{Q}_{\mathrm{c}}=150 * 4$

$$
=600 \mathrm{KJ}
$$

Heat Rejection $\left(\mathrm{Q}_{\mathrm{h}}\right)=53 * 10 * 326+0.5(10)^{2} * 2.1-$ $0.025(326-283)$

$$
=172883.9 \text { Joules }
$$$$
=173 \mathrm{KJ}
$$

For 4 Peltier modules $\mathrm{Q}_{\mathrm{h}}=173 * 4$

$$
=692 \mathrm{KJ}
$$

Coefficient of performance $=Q_{c} / Q_{h}-Q_{c}$

$$
=600 / 692-600
$$$$
=6.52
$$

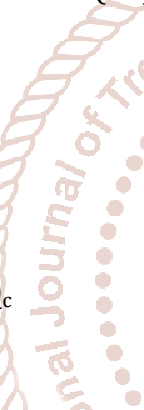

COP of TER (Thermo electric refrigerator) Outer dimensions

Breadth $=30 \mathrm{~cm}$ Length $=40 \mathrm{~cm}$

Height $=50 \mathrm{~cm}$

Inner dimensions

Length $=33 \mathrm{~cm}$

Height $=34 \mathrm{~cm}$

Breadth $=23 \mathrm{~cm}$

\section{Volume of the fridge}

Volume Outer $=$ Length*Breadth*Height

$=40 * 30 * 50=60000 \mathrm{~cm}^{3}$

$=0.06 \mathrm{~m}^{3}$

Volume Inner $=$ Length*Breadth $*$ Height

$=33 * 23 * 34=25806 \mathrm{~cm}^{3}$

$=0.0258 \mathrm{~m}^{3}$

Let the mass of the water inside the refrigerator be $M_{w}$ Let Specific heat capacity of water at constant pressure be $C_{p}$ $\mathrm{Mw}=$ Volume of water in the refrigerator $*$ Density of water at $300 \mathrm{~K}$

Mass of the water in the box be $\mathrm{M}_{\mathrm{w}}=$ Volume of water in the box * Density of water at $300 \mathrm{~K}$

$$
=100 * 10^{-6 * 1000} \quad=0.1 \mathrm{Kg}
$$

1. Input Power $=$ Voltage $*$ Current

$=(12 \mathrm{~V} * 9 \mathrm{~A})=108$ Watts

2. Initial Temperature $=305 \mathrm{~K}$

3. Final Temperature $=300.7 \mathrm{~K}$

4. Total amount of heat removed $=$ Total cooling effect produced

$=\mathrm{M}_{\mathrm{w}} * \mathrm{C}_{\mathrm{p}} *$ (Change in temperature)

$=0.1 * 4.12 * 4.3$

$=1.7716 \mathrm{KJ}=1771.6 \mathrm{~J}$

5. Input Work $=$ Input power $*$ Time (in seconds)

$=108 \mathrm{~W} * 60$ seconds

$=6480 \mathrm{~J}$

6. Coefficient of performance

$=$ Refrigeration effect / Input work

$=1771.6 / 6480$

$=0.27$

After conducting tests on designed Thermoelectric refrigerator following conclusions are drawn. From the experimentation it is observed that in TER the refrigeration effect can be increased as compared to single thermo electric refrigerator system. Experimental results show that the coefficient of performance(COP) of Thermoelectric refrigeration system is found to be 0.27

\section{REFERENCES}

[1] Manoj Kumar., Chattopadhyay and Neogi., A review on developments of thermoelectric refrigeration and air conditioning systems: a novel potential green refrigeration and air conditioning technology. International Journal of Emerging Technology and Advanced Engineering, 38,362-367, (2013).

[2] Manoj S., \& Walke., Thermoelectric Air Cooling for Cars. International Journal of Engineering Science and Technology, 40(5), 2381-2394, (2011).

[3] Yadav and Nirves., Review on Thermoelectric materials and applications. International Journal for Scientific Research \& Development, 1,413-417, (2013).

[4] Maneewan.,Tipsaenpromand,Lertsatitthanakorn.,Ther mal comfort study of a compact thermoelectric air conditioner. Journal of electronic materials, 39(9), 1659-1664, (2010).

[5] Huang B., Chin C.J., and Duang C.L., A design method of thermoelectric cooler. International Journal of Refrigeration, 23,208-218, (1999).

[6] Astrain D., Vian J.G., \& Dominguez M., Increase of COP in the thermoelectric refrigeration by the optimization of heat dissipation. Applied Thermal Engineering, 23, 2183-2200, (2003).

[7] Shen., Xiao., Chen \& Wang., Investigation of a novel thermoelectric radiant air-conditioning system. Journal of Energy and Buildings, 59, 123-132, (2012).

[8] Virjoghe., Diana., Marcel \& Florin., Numerical simulation of Thermoelectric System. latest trends on systems,15(2), 630-635, (2009).

[9] Riffat and Guoquan., Comparitive investigation of thermoelectric air- conditioners versus vapour 
International Journal of Trend in Scientific Research and Development (IJTSRD) @ www.ijtsrd.com eISSN: 2456-6470

compression and absorption air- conditioners. Journal of Applied Thermal Engineering, 24, 1979-1993, (2004).

[10] Sujin., Vora and Seetawan., Analysing of Thermoelectric Refrigerator Performance. Proceedings of the 2ndInternational Science, Social-Science, Engineering and Energy Conference, 25,154-159, (2000).

[11] Wei., Jinzhi., Jingxin \& Chen., Theoretical and experimental investigation on a thermoelectric cooling and heating system driven by solar. Applied Energy, 107, 89-97, (2013).

[12] ElCosnier W., Gilles M., Lingai., An experimental and numerical study of a thermoelectric air-cooling and air- heating system. International journal of refrigeration,31,1051-1062, (2008).

[13] Riffat and Qiu., Design and characterization of a cylindrical water-cooled heat sink for thermoelectric air-conditioners. International journal of energy research, 30, 67-80, (2005).

[14] Mayank Awasthi and KV Mali., A review on design and development of thermo electric refrigerator ISSN 2278 - 0149 www.ijmerr.com Vol. 1, No. 3, October 2012.

[15] Sagar D. Patil and Kiran D. Devade., A review on International Journal of Modern Trends in Engineering and Research (IJMTER) Volume 02, Issue 07, [July2015]. 